\title{
An Investigation of the Relationship between Resilience, Mindfulness, and Academic Self-Efficacy
}

\author{
Michelle D. Keye, Aileen M. Pidgeon \\ Faculty of Humanities and Social Sciences, Bond Univertsity, Gold Coast, Australia \\ Email: michelle_keye@hotmail.com
}

Received August 2013

\begin{abstract}
Resilience, mindfulness, and academic self-efficacy are topics of interests to psychologists; however, little is known about the relationships among the three. The primary purpose of this research was to explore the role of mindfulness and academic self-efficacy in predicting resilience among university students. 141 participants $(\mathrm{m}=39, \mathrm{f}=102)$ completed The Freiburg Mindfulness Inventory, The Beliefs in Educational Success Test, and The Connor Davidson Resilience Scale. The results found that in the regression models, mindfulness and academic self-efficacy were significant predictors of resilience. This finding suggests that mindfulness and academic self-efficacy have a significant impact on resilience.
\end{abstract}

Keywords: Resilience; Mindfulness; Academic Self-Efficacy

\section{Introduction}

The present study investigates the relationship between mindfulness, academic self-efficacy, and resilience. Resilience is referred to as the ability to "sustain psychological stability in the face of stress" (Combes-Malcome, 2007: p. 20). Positive outcomes associated with resilience are the alleviation of the negative effects of stress, the promotion of adaptation, and the development of effective coping skills to deal with change and adversity (Ahern, Kiehl, Sole, \& Byers, 2006; Richardson, Neiger, Jensen, \& Kumpfer, 1990). Resilience is an important factor for preventing the development of psychopathology and maintaining optimal functioning, physical health and psychological health despite stressful life circumstances (Ryff \& Singer, 2003). Many researchers believe that resilience can be strengthened because it is not a "hard-wired" personality trait possessed by only some individuals, and is the result of the development of protective factors (Reivich \& Shatte, 2002). Therefore, strengthening the protective factors associated with resilience will strengthen resilience.

Thompson, Arnkoff, and Glass (2011) have proposed that mindfulness is associated with resilience, and Greason \& Cashwell (2009) research found evidence of an association between mindfulness and self-efficacy. These findings suggest that mindfulness and self-efficacy show potential to be protective factors to strengthening resilience (Hamill, 2003). However, to date there is little research supporting the predictive abilities of mindfulness and self-efficacy on resilience. Therefore the aim of the current study will be to investigate the relationship between mindfulness and self-efficacy and their potential contribution to resilience.

\section{Resilience}

In recent years, resilience has been recognized as a developmental process, reflecting the capacity for positive adjustment in difficult life circumstances as opposed to a trait (Lightsey, 2006). For the purpose of the present study, resilience will be defined as the ability an individual has to recover from distressing and challenging life events with increased knowledge to adaptively cope with similar adverse situations in the future. This definition is based on Flach's (1989) theory of resilience, which states that resilience is made up of the psychological strengths required to successfully navigate change. Flach's (1989) theory of resilience is based on the "Law of Disruption and Re-integration", which suggests that the act of "falling apart”, or being distressed by change, is actually a necessary part of learning to cope with stressful life events.

Flach describes disruption as the effect of life events, which remove individuals from their own personal homeostasis. As each person is unique, they also have unique levels of disruption that they can manage. Disruption is an unpleasant experience, even painful, and as such, Flach suggest that individuals experiencing disruption are forced to look inward and adapt to meet the new challenge. Flach's theory postulates that temporary challenges are good opportunities to deal with old hurts, discover new coping mechanisms, and generally re-organise one's perspective on life. This process is called re-integration and involves re-forming ones view of the world and of oneself (Flach, 1989). When disruption occurs, individuals try to rebuild their life, their homeostasis, by problem solving and looking at the situation from a different perspective. Each individual has a unique time-frame for the process of re-integration which depends not only on the level of distress caused by the life event, but by the capacity of that individual and the traits they possess (Flach, 1989).

Over the last few decades, there has been research aiming to discover what these character traits are and certain traits, including self-efficacy, creative problem solving skills, personal introspection, and the ability to engage with the present, have consistently been shown to be associated with resilience (Thompson, Arnkoff, \& Glass, 2011; VanBreda, 2001). Recently, research indicates that many of these traits associated with resilience, are also associated with mindfulness (Van Breda, 2001) and self-efficacy (Lightsey, 2006). 


\section{Mindfulness}

Although Buddhist philosophy states that cultivating mindfulness is important to enhance well-being (Baer, 2003), mindfulness is a relatively new construct in the field of psychology (Brown, Marquis, \& Guiffrida, 2013; Catalino \& Fredrickson, 2011). Mindfulness is a skill, which enhances adaptive coping to stressful events by the self-regulation of attention towards the immediate experience, and an open and accepting orientation towards one's experience of the present (Bishop et al., 2004). Thoughts and emotions that enter an individual's awareness are observed, and not expanded on or evaluated, with attention being redirected towards the breath in the present moment (Chiesa \& Malinowski, 2011).

A theory of mindfulness proposed by Bishop et al. (2004) postulates that mindfulness operates by individuals learning to abandon their efforts to forcibly control their negative thoughts and to instead acknowledge that the thoughts and emotions are present. The skill of mindfulness raises awareness to the transient nature of these negative thoughts, emotions, and body sensations, which leads to more flexible and objective responses rather than reactions (Keng, Smoski, \& Robins, 2011). This is contrasted with habitual judgments and interpretations of stimuli that enter awareness, which trigger strong emotions and reactions, and subsequently contribute to poor mental health (Marchand, 2012).

\section{Resilience and Mindfulness}

A review of the literature revealed an association between mindfulness and resilience. Lightsey (2006) postulates that resilience can be taught through psychological interventions, and Van Breda (2001) postulates that mindfulness-based training may be an efficacious intervention for increasing resilience. A study by Jha, Stanley, Kiyonaga, Wong, and Gelfand (2010) supported the notion of a relationship between mindfulness and resilience. The Jha et al. (2010) study showed that Mindfulness-Based Fitness Training (MMFT) shows potential as an effective method of increasing the resilience and psychological well being of soldiers whose deployment and occupation increases the risk of psychological trauma. Further support for an association between resilience and mindfulness was found by Chavers (2013) research, which found a significant correlation between mindfulness and resilience, with mindfulness being a significant predictor of resilience.

\section{Academic Self-Efficacy}

Self-efficacy has been found to be associated with increased resilience (Chemers, Hu, \& Garcia, 2000; Pajares, 1996). Selfefficacy is the interpretation individuals give to their own performance and achievement (Hudson, 2007). This interpretation is formed by existing self-beliefs and has been found to directly affect an individual's motivation to succeed in future situations (Pajares, 1996). A plethora of research has shown that academic self-efficacy has a positive relationship with university grades (Hudson, 2007) and persistence to succeed in future tasks (Bouffard-Bouchard, Parent, \& Larivee, 1991).

\section{Resilience and Academic Self-Efficacy}

A number of theories postulate an association between academic self-efficacy and resilience. For example, Lightsey's
(2006) theory, which proposes that individual's self-efficacy is central to their level of resilience. This theory has been supported empirically, by a study conducted by Speight (2009) who found a positive relationship between self-efficacy and resilience in high school students. Although several studies have shown a relationship between resilience and self-efficacy, few have examined the relationship between academic self-efficacy and resilience. Therefore, the present study will further our understanding of this relationship by exploring the predictive ability of academic self-efficacy on resilience.

\section{The Current Study}

The aim of the current study is to investigate protective factors of resilience by examining the predictive abilities of mindfulness and academic self-efficacy on resilience.

Therefore, it is hypothesized that:

$\mathrm{H}_{1}$ : There will be a significant positive correlation between the predictor variables for the regression model, with mindfulness and academic self-efficacy showing significant correlations with each other.

$\mathrm{H}_{2}$ : Mindfulness and academic self-efficacy will be significant predictors of resilience with higher levels of mindfulness and academic self-efficacy predicting higher levels of resilience.

\section{Method}

\section{Participants}

Participants were 39 male and 102 female university students $(N=141)$. Inclusion criteria for this study required participants to be aged 18 years or above.

\section{Measures}

The Freiburg Mindfulness Inventory (FMI) (Walach et al., 2006) is a 14-item scale measuring an individual's experience of mindfulness. A total mindfulness score is given by summing participants' scores across all items, with greater scores indicating greater levels of mindfulness.

The Beliefs in Educational Success Test (BEST). The BEST (Majer, 2006), is a 10-item scale measuring an individual's belief in their ability to succeed academically. Values increase in increments of 10 with higher scores indicating greater academic self-efficacy; possible total scores for the BEST range from 100 - 1000.

The Connor Davidson-Resilience Scale (CD-RISC). The CD-RISC (Connor \& Davidson, 2003) is a 25-item scale which rates how individuals have felt over the last month and their stress coping ability. A total score is given by summing an individual's response across all items with higher scores indicating higher levels of resilience.

\section{Results}

Participants' total scores for mindfulness, academic self-efficacy, and resilience were calculated by summing each item within each scale. Mean and standard deviations for each variable can be seen in Table $\mathbf{1}$.

Table 2 shows the correlations between the predictor and criterion variables. It can be seen that there is a significant correlation between mindfulness and academic self-efficacy, $r=.43$, 
Table 1.

Number of participants, mean scores, and standard deviations for mindfulness, academic self-efficacy, and resilience.

\begin{tabular}{lccc}
\hline & $N$ & $M$ & $S D$ \\
\hline Mindfulness & 141 & 37.55 & 6.55 \\
Academic Self-efficacy & 141 & 775.25 & 130.94 \\
Resilience & 141 & 90.72 & 12.59 \\
\hline
\end{tabular}

Note: $N=$ Number of Participants, $M=$ Mean Score, $S D=$ Standard Deviation.

Table 2.

Pearson correlation coefficients for predictor and criterion variables.

\begin{tabular}{ccc}
\hline & Mindfulness & Resilience \\
\hline Resilience & $.67^{*}$ & \\
Academic Self-efficacy & $.43^{*}$ & $.65^{*}$ \\
\hline
\end{tabular}

Note: ${ }^{*}$ Correlation is significant at $p<.000$.

$p<.000$, supporting hypothesis one.

A hierarchical regression was conducted to evaluate the predictive ability of mindfulness and academic self-efficacy on the criterion variable of resilience. Both mindfulness and academic self-efficacy were found to be significant predictors of resilience, $F(1,139)=110.39, p<.000$, and $F(2,138)=104.44, p$ $<.000$ respectively, supporting hypothesis two.

When used as predictors in the regression model, both mindfulness (model 1) and academic self-efficacy (model 2) were found to have large correlations with the criterion variable as can be seen by the $R$ values in Table 3. Furthermore, Table 3 shows the adjusted $R^{2}$ values, which were all found to be moderately sized and significant. Mindfulness accounted for $44 \%$ of the total outcome variance, and academic self-efficacy accounted for $16 \%$ of the total outcome variance of the resilience model. Model 2 shows that combined, mindfulness and academic self-efficacy accounted for $60 \%$ of the total variance in the resilience model.

Table 4 shows the standardized coefficients $(\beta)$ for the regression model. Of the predictor variables in the regression model, both mindfulness and academic self-efficacy were found to be significant predictors; however, mindfulness was found to be the variable contributing most highly to the regression model of resilience.

\section{Discussion}

The purpose of the current study was to investigate the relationships between resilience, mindfulness, and academic selfefficacy. Adequate correlations were found between the pair of predictor variables, supporting hypothesis one. The second hypothesis, which predicted that mindfulness and academic selfefficacy would predict resilience, was supported as the results found that both mindfulness and academic self-efficacy were significant predictors of resilience. The regression model showed that mindfulness and academic self-efficacy combined accounted for a large amount of the total variance in the resilience model. These results support Flach's (1989) theory of resilience that suggests mindfulness and academic self-efficacy to be part of the repertoire of psychological strengths, which allow individuals to successfully navigate change. In the case of self-efficacy, the results from the current study supports Lightsey's (2006) theory, which proposes that an individual's
Table 3.

The regression models for the predictor variables (mindfulness and academic self-efficacy) and the criterion of resilience.

\begin{tabular}{cccccc}
\hline & $R$ & Adjusted $R^{2}$ & $R^{2}$ Change & df1 & df2 \\
\hline Model $1^{\mathrm{a}}$ & $.67^{*}$ & .44 & .44 & 1 & 139 \\
Model $2^{\mathrm{b}}$ & $.78^{*}$ & .60 & .16 & 1 & 138 \\
\hline
\end{tabular}

Note: ${ }^{a}$ Predictors: (constant), total mindfulness; ${ }^{\mathrm{b}}$ Predictors: (constant), total mindfulness, total academic self-efficacy; ${ }^{*}$ Significant at $p<.000$.

Table 4.

coefficients for regression models showing size of significant predictor variables (mindfulness and academic self-efficacy).

\begin{tabular}{ccccc}
\hline & $B$ & $S E$ & $\beta$ & $95 \%$ CI for $B$ \\
\hline Model 1 & & & & \\
Constant & 42.73 & 4.64 & & {$[33.56,51.90]$} \\
Mindfulness & 1.28 & .12 & $.67^{*}$ & {$[1.04,1.52]$} \\
Model 2 & & & & \\
Constant & 23.5 & 4.71 & & {$[14.21,32.81]$} \\
Mindfulness & .91 & .15 & $.47^{*}$ & {$[.69,1.14]$} \\
A. Self-efficacy & .04 & .01 & $.44^{*}$ & {$[.03, .05]$} \\
\hline
\end{tabular}

Note: A. Self-efficacy = Academic Self-efficacy; CI = Confidence Interval; ${ }^{*} p$ $<.000$.

self-efficacy is central to their level of resilience.

A number of limitations must be considered when examining these results. Firstly, while the findings of the present study are theoretically grounded, the variables were not manipulated in an experimental design. As such, the researchers acknowledge that there may be other variables, which are operating within the relationships found, that may be having a great influence on the results. Furthermore, as the majority of participants in the sample were female university students, there is a limited ability to generalize the results. It is recommended that future research use a more diverse sample of university students.

The current findings have implications for future research as they expand upon current knowledge of the protective factors that strengthen resilience. For example, if mindfulness and academic self-efficacy predict resilience in students, then developing interventions that target increasing students' mindfulness and academic self-efficacy may be beneficial in strengthening resilience. As there is growing research showing the importance of resilience in positive mental health (Lightsey, 2006; Richardson, Neiger, Jensen, \& Kumpfer, 1990), potential new interventions for strengthening resilience may be beneficial for mental health professionals.

In conclusion, the present study provides an investigation of the relationship between resilience, mindfulness, and academic self-efficacy. Given the finding that mindfulness and academic self-efficacy are significant predictors of resilience it is recommended that future studies use experimental methods to replicate these findings in order to gain a more comprehensive understanding of these relationships and their applications to the positive perspective of mental health.

\section{REFERENCES}

Ahern, N. R., Kiehl, E. M., Sole, M. L., \& Byers, J. (2006). A review of 
instruments measuring resilience. Issues in Comprehensive Pediatric Nursing, 29, 103-125. http://dx.doi.org/10.1080/01460860600677643

Baer, R. A. (2003). Mindfulness training as a clinical intervention: A conceptual and empirical review. Clinical Psychology: Science and Practice, 10, 125-143. http://dx.doi.org/10.1093/clipsy.bpg015

Bishop, S. R., Lau, M., Shapiro, S., Carlson, L., Anderson, N. D., Carmody, J. et al. (2004). Mindfulness: A proposed operational definition. Clinical Psychology: Science and Practice, 11, 230-241. http://dx.doi.org/10.1093/clipsy.bph077

Bouffard-Bouchard, T., Parent, S., \& Larivee, S. (1991). Influence of self-efficacy on self-regulation and performance among junior and senior high school aged students. International Journal of Behavioural Development, 14, 153-164. http://dx.doi.org/10.1177/016502549101400203

Brown, A., Marquis, A., \& Guiffrida, D. (2013). Mindfulness-based interventions in counseling. Journal of Counselling and Development, 91, 96-104. http://dx.doi.org/10.1002/j.1556-6676.2013.00077.x

Catalino, L. I., \& Fredrickson, B. L. (2011). A Tuesday in the life of a flourisher: The role of positive emotional reactivity in optimal mental health. Emotion, 11, 938-950. http://dx.doi.org/10.1037/a0024889

Chavers, D. J. (2013). Relationships between spirituality, religiosity, mindfulness, personality, and resilience. Doctoral Dissertation, Alabama: University of South Alabama.

Chemers, M. M., Hu, L., \& Garcia, B. F. (2001). Academic self-efficacy and first year college student performance and adjustment. Journal of Educational Psychology, 93, 55-64. http://dx.doi.org/10.1037/0022-0663.93.1.55

Chiesa, A., \& Malinowski, P. (2011). Mindfulness-based approaches: Are they all the same? Journal of Clinical Psychology, 67, 404-424. http://dx.doi.org/10.1002/jclp.20776

Combes-Malcome, L. A. (2007). Beginning teachers, resilience and retention. Doctoral Dissertation, San Marcos: Texas State University.

Connor, K. M., \& Davidson, J. R. T. (2003). Development of a new resilience scale: The connor-davidson resilience scale (cd-risc). Depression and Anxiety, 18, 76-82. http://dx.doi.org/10.1002/da.10113

Flach, F. F. (1989). Resilience: Discovering new strength at times of stress. New York: Ballantine Books.

Greason, P. B., \& Cashwell. C. S. (2009). Mindfulness and counselling self-efficacy: The mediating role of attention and empathy. Counsellor Education and Supervision, 49, 2-19. http://dx.doi.org/10.1002/j.1556-6978.2009.tb00083.x

Hamill, S. K. (2003) Resilience and self-efficacy: The importance of efficacy beliefs and coping mechanisms in resilient adolescents. Colgate University Journal of the Sciences, 35, 115-146. http://groups.colgate.edu/cjs/student_papers/2003/Hamill.pdf

Hudson, W. E. (2007). The relationship between academic self-efficacy and resilience to grades of students admitted under special criteria. Doctoral Dissertation, Tallahassee: The Florida State University.

Jha, A. P., Stanley, E. A., Kiyonaga, A., Wong, L., \& Gelfand, L. (2010). Examining the protective effects of mindfulness training on working memory capacity and affective experience. Emotion, 10, 5464. http://dx.doi.org/10.1037/a0018438

Keng, S., Smoski, M. J., \& Robins, C. J. (2011). Effects of mindfulness on psychological health: A review of empirical studies. Clinical Psychology Review, 31, 1041-1056. http://dx.doi.org/10.1016/j.cpr.2011.04.006

Lightsey, O. R. (2006). Resilience, meaning, and well-being. The Counselling Psychologist, 34, 96-107. http://dx.doi.org/10.1177/0011000005282369

Majer, J. M. (2006). Beliefs in Educational Success Test (BEST). Unpublished Instrument.

Marchand, W. R. (2012). Mindfulness-based stress reduction, mindfulness-based cognitive therapy, and zen meditation for depression, anxiety, pain, and psychological distress. Journal of Psychiatric Practice, $18,233-252$. http://dx.doi.org/10.1097/01.pra.0000416014.53215.86

Pajares, F. (1996). Self-efficacy beliefs in academic settings. Review of Educational Research, 66, 543-578. http://dx.doi.org/10.3102/00346543066004543

Reivich, K. \& Shatte, A. (2002). The resilience factor. New York: Broadway Books.

Richardson, G. E., Neiger, B.L., Jensen, S., \& Kumpfer, K. L. (1990). The resilience model. Health Education, 21, 33-39.

Ryff, C. D., \& Singer, B. (2003). Flourishing under fire: Resilience as a prototype of challenged thriving. In C. L. M. Keyes, \& J. Haidt (Eds.), Positive psychology and the life well-lived (pp. 15-36). Washington DC: APA. http://dx.doi.org/10.1037/10594-001

Speight, N. P. (2009). The relationship between self-efficacy, resilience and academic achievement among African American urban adolescents. Doctoral Dissertation, Washington DC: Howard University.

Thompson, R. W., Arnkoff, D. B., \& Glass, C. R. (2011). Conceptualizing mindfulness and acceptance as components of psychological resilience to trauma. Trauma, Violence and Abuse, 12, 220-235. http://dx.doi.org/10.1177/1524838011416375

Van Breda, A. D. (2001). Resilience theory: A literature review (Research Report MPI/R/104/12/1/4). South African Military Psychological Institute. http://vanbreda.org/adrian/resilience/resilience_theory_review.pdf

Walach, H., Buchheld, N., Buttenmüller, V., Kleinknecht, N., \& Schmidt, S. (2006). Measuring mindfulness-The Freiburg mindfulness inventory (FMI). Personality and Individual Differences, 40, 15431555. http://dx.doi.org/10.1016/j.paid.2005.11.025 